Int. J. Electrochem. Sci., 15 (2020) $1412-1425$

\title{
Expired Drug Theophylline as Potential Corrosion Inhibitor for 7075 Aluminium Alloy in 1M NaOH Solution
}

\author{
Peng Su ${ }^{l}$, Lintao $\mathrm{Li}^{l}$, Weiliang $\mathrm{Li}^{1}$, Chuanyan Huang ${ }^{1}$, Xiaohong Wang, ${ }^{2, *}$ Hao Liu ${ }^{2}$, \\ Ambrish Singh ${ }^{2 *}$ \\ ${ }^{1}$ Research Institute of Engineering Technology, SINOPEC Northwest Oilfield Company, Urumqi- \\ 830011, China. \\ ${ }^{2}$ School of Material Science and Engineering (Southwest Petroleum University), Chengdu, Sichuan \\ 610500, China. \\ *E-mail: vishisingh4uall@gmail.com; xhwang3368@swpu.edu.cn
}

doi: $10.20964 / 2020.02 .25$

Received: 26 September 2019 / Accepted: 22 November 2019 / Published: 31 December 2019

\begin{abstract}
The expired drug Theophylline (DT) was used as impending corrosion inhibitor for 7075 aluminium in saline environment. The investigations were done using gravimetric tests, electrochemical tests, surface characterizations, and quantum calculations. Gravimetric tests were done with respect to time, temperature and inhibitor concentration. The studies showed the good efficiency in presence of DT. Electrochemical tests included impedance and polarization studies. Impedance results showed the surge in charge transfer resistance values with rise in DT concentration. Localized electrochemical behavior was determined using scanning electrochemical microscopy (SECM). SECM showed the inductive surface in presence of DT and conductive in it absence. Surface characterization tests consist of contact angle, and scanning electrochemical microscopy (SEM). Quantum simulations were done using Gaussian 9.0 software using density functional theory (DFT) to get computational parameters that can support the experimental findings. All the results showed that the Theophylline drug can inhibit the 7075 aluminium alloy in saline media effectively.
\end{abstract}

Keywords: Aluminium alloy; Corrosion; Inhibition; SEM; SECM; DFT

\section{FULL TEXT}

(C) 2020 The Authors. Published by ESG (www.electrochemsci.org). This article is an open access article distributed under the terms and conditions of the Creative Commons Attribution license (http://creativecommons.org/licenses/by/4.0/). 